\title{
A structural state model for interpreting residual strength transition behavior of land-sliding soils with different clay fractions
}

\section{Sohail Akhtar}

Concordia University

Biao Li ( $D$ biao.li@concordia.ca )

Concordia University https://orcid.org/0000-0002-7971-0085

\section{Research Article}

Keywords: Residual friction angle, structural state, clay size fraction, smectite content, percolation theory

Posted Date: March 1st, 2022

DOI: https://doi.org/10.21203/rs.3.rs-1297619/v1

License: (c) (1) This work is licensed under a Creative Commons Attribution 4.0 International License.

Read Full License 


\section{Abstract}

Residual friction angles of soils are commonly determined by laboratory tests, which are time-consuming and costly. It is more desirable to find practical means of estimating the residual strength of soils in the slip zones. Previous researchers attempted to correlate the soil residual strength with clay fraction or Atterberg limits using empirical equations. A large amount of laboratory data demonstrate that the magnitude of residual strength decreases with the increase in the clay content. However, the physical mechanisms of such correlation are not well interpreted. In addition, the decreasing trend has never been modeled with a unique empirical or semi-empirical equation because of the variety of influencing factors such as the clay mineralogy and the applied normal stress. In this study, a new approach is proposed to estimate the residual friction angles of land-sliding soils. The residual friction angle of soils is derived as a weighted average result of the friction angles of nonclay minerals and clay matrix. A structural state coefficient is used as the weight function, and the plasticity index is used to consider the difference in clay mineralogy. The percolation theory is used to physically explain and illustrate the structural state transitional behavior of soils with different clay fractions. The results demonstrate that the semiempirical approach can be used for predicting residual friction angles of a wide range of soils that differ in geology, soil type, mineralogical properties, and shear strength. The effects of applied normal stress, pore fluid salinity, and particle size on the estimations are also discussed.

\section{Introduction}

Residual strength of soils is the most important parameter to evaluate their stability and it is crucial for understanding the landslide reactivation mechanisms (Skempton 1985; Zhang et al. 2015). The residual strength parameter such as the residual friction angle of soils is commonly determined by the laboratory reversal direct shear test (Townsend and Gilbert 1973; Stark and Hussain 2010), the ring shear test (Bishop 1971; Gibo et al. 1992; Tiwari and Marui 2001, 2004, 2005; Eid et al. 2016), or the in-situ direct shear tests (Chen and Liu 2014; Wen et al. 2007). Those strength tests must fulfill the sample's residual state and need to be carried out at very low deformation rates. A landslide usually covers a wide range of study area, which gives uncertainty in soil compositions. A large quantity of strength results requires a comprehensive analysis (Ren et al. 2021). Therefore, it is also necessary to efficiently conduct a preliminary estimate of residual friction angles of land-sliding soils using easily obtained soil properties such as clay fraction and Atterberg limits (Voight 1973; Cancelli 1977; Wesley 2003; Tiwari and Marui 2003; Wen et al. 2007; Stark and Hussain 2013; Eid et al. 2016). Voight (1973) suggested that there is an inverse relationship between residual strength and plastic index. Cancelli (1977) presented a power law empirical correlation between the residual strength and liquid limit for the over consolidated clay. Collota et al. (1989) also proposed the empirical correlation, which determines the residual strength as a function of clay fraction, liquid limit, and plastic index. Moreover, a complex correlation was developed by Tsifoutidis (1993), which considers the complete particle size ranges of soil. Some of previous experimental data demonstrate that the decreasing magnitude of residual strength with increasing clay content varies significantly for soils with different types of dominant clay minerals (Lupini et al. 1981; 
Mesri and Cepeda-Diaz 1986; Nakamura et al. 2010; Skempton, 1985; Suzuki et al. 2007). Several researchers also presented empirical correlations that use liquid limit, clay-sized fraction, and effective normal stress to capture the variability and stress-dependent nature of residual strength of clay soils (Lupini et al. 1981; Kalteziotis 1993; Belokas 2015; Stark and Eid 1994). It should be noted that the decreasing trend was only modeled mathematically in previous studies with limited theoretical support on the physical mechanisms.

In this study, a structural state concept was quantitatively included to model the residual strength transition behavior for soils with different clay fractions. The percolation theory is used to physically explain the structural state transitional behavior. Some factors affecting the residual strengths of landsliding soils are also discussed.

\section{Structural State Model}

Structural states of framework-supported by quartz grains, and matrix-supported by clay particles have been introduced to interpret acoustic velocity changes (Yin 1992), permeability reduction (Crawford et al. 2008), and strength degradation (Lupini et al. 1981; Skempton 1985; Tembe et al. 2010) in clay-related geomaterials due to the increase in the clay fraction. However, the concept of structural state was only used as a qualitative term in previous researches. Li and Wong (2016) proposed a $c_{m}$-model (clay matrix model) to quantify the structural state of soft mudrocks. The $c_{m}$-model was successfully applied to estimate the preferred fabric orientation distributions ( $\mathrm{Li}$ and Wong 2017a) and anisotropic thermal strain behavior of soft mudrocks (Li and Wong 2017b). The proposed $c_{m}$-model will be used herein to estimate the residual friction angle of soils. The theoretical support for this $C_{m}$-model is included in the discussion section, where the percolation theory is applied.

As shown in Fig. 1, and Eq. (1), the structural state coefficient $C_{m}$ is a function of clay fraction, $C_{f}$

$$
c_{m}=\frac{\tanh \left(\frac{c_{f}-\mathrm{A}}{\mathrm{B}}\right)+1}{2}
$$

1

where $\mathrm{A}$ and $\mathrm{B}$ are two parameters of the $C_{m}$-model. With a low clay fraction, soils have a structural state of framework-supported, and most of the friction behaviors occur among those contacts of non-clay fraction. With the increase in the clay fraction, soils transfer to a state of clay matrix-supported, and most of the friction behaviors are involved in those contacts among clay minerals (Fig. 1).

The $C_{m}$-model indicates how active clay minerals serve as the supporting matrix in soil. It can also be treated as a weight function. By taking into account the structural state, the overall residual friction angle of the soil, $\phi_{r}$ can be estimated by: 


$$
\phi_{r}=\phi_{r}^{c} C_{m}+\phi_{r}^{n c}\left(1-c_{m}\right)
$$

2

where $\phi_{r}{ }^{C}$ is the residual friction angle of clay matrix, and $\phi_{r}{ }^{n C}$ is the residual friction angle of non-clay minerals. By combining Eq. (1) and Eq. (2), $\phi_{r}$ can be expressed using:

$$
\phi_{r}^{c} \frac{\tanh \left(\frac{c_{f}-\mathrm{A}}{\mathrm{B}}\right)+1}{2}+\phi_{r}{ }^{n c}\left(1-\frac{\tanh \left(\frac{c_{f}-\mathrm{A}}{\mathrm{B}}\right)+1}{2}\right)
$$

3

For a specific type of soil, $\phi_{r}{ }^{C}$ and $\phi_{r}{ }^{n c}$ can be treated as constants, and values of residual friction angle $\phi_{r}$ are dependent on the clay fraction, $c_{f}$ With a group of measured $\phi_{r}$ and $c_{f}$ parameters $\mathrm{A}$ and $\mathrm{B}$ can be obtained using curving fitting.

\section{Estimating Residual Friction Angles Based On The Structural State Model}

Measured residual friction angles of worldwide soils with clay fraction data were used for the modeling analysis herein. The soils are mainly located in Asia (Nakumura et al. 2010), North American (Stark and Hussain 2010; Eid et al. 2016), and Europe (Kalteziotis 1993). Measured residual fictional angle results were plotted against the clay fraction data and shown in Fig. 2. In this study, particle size $<0.005 \mathrm{~mm}$ is treated as the clay group. The upper plateau for friction angle $\phi^{n c}$ depends on the grain size distribution and the shape of non-clay mineral grains (Horn and Deere 1962; Salimi et al. 2008). The friction angle increases with the increase in larger non-clay minerals and will yield higher values for angular shape grains. According to the experimental results by Nakumura et al. (2010), the residual friction angle of sand, $\phi_{r}{ }^{n C}$ is about 34 degrees, where major nonclay particles are composed of sand-sized quartz. If nonclay particles are composed of different minerals and have different particle sizes, a different $\phi_{r}{ }^{n c}$ value should be applied. Accurate $\phi_{r}{ }^{n c}$ values can be determined by carrying out shear tests on non-clay parts of the collected samples. When the clay fraction is more than 0.7 , soils display a very little change in the residual strength with an increase of clay fraction. Thus, we postulate that those soils (with a clay fraction of more than 0.7 ) are fully supported with clay matrix. As shown in Fig. 2, the residual friction angles of those high clay fraction soils are approaching 5 degrees. The value of 5 degrees is treated as the residual friction angle of the clay matrix, $\phi_{r}{ }^{c}$ herein. The decreasing trends for different soils are modeled and displayed in Fig. 2 by applying the proposed simplified approach displayed in Eq. (2). The generated structural state parameters using nonlinear curve fitting are included in Table 1. In general, structural state parameters ( $A$ and $B$ ) dictate the shape of the sigmoidal curve, which was affected with 
the soil types and the geological origins (Fig. 2). It should be noted that Eid et al. (2016) conducted an extensive torsional ring shear testing program of soils at the wide range of effective normal stress (10 to $700 \mathrm{kPa}$ ). We only include the results with large normal stress (more than $200 \mathrm{kPa}$ ) in (Fig. 2c).

Table 1

Structural state parameters for estimating the residual strength of soils by applying the $c_{m}$-model

\begin{tabular}{|llll|}
\hline Experimental data source & A & B & $\mathbf{R}^{2}$ \\
\hline Kalteziotis (1993) & 0.46 & 0.25 & 0.863 \\
\hline Stark and Hussain (2010) & 0.35 & 0.24 & 0.996 \\
\hline Nakumura et al. (2010) & 0.41 & 0.11 & 0.897 \\
\hline Eid et al. (2016) & 0.36 & 0.33 & 0.737 \\
\hline All data & 0.41 & 0.26 & 0.795 \\
\hline Notes: A and B are parameters for the $C_{m}$-model, $\mathrm{R}^{2}$ is the coefficient of determination. \\
\hline
\end{tabular}

A general trend for all the data illustrated in Fig. 2 is modeled and shown in Fig. 3. The obtained values of 0.41 and 0.26 for the structural state parameters $A$ and $B$ can be treated as practical values for worldwide landslide soils that differ in geological origin.

\section{Discussions}

\subsection{Structural state model and percolation theory}

The structural state transitional behavior shown in Fig. 1 can be explained by using the percolation theory (Malthe-Sorenssen 2015), where the critical clay fraction corresponds to the transition point of the structural state. Soils are mainly composed of non-clay minerals, clay minerals, and water. Among them, clay minerals (e.g., smectite, illite, kaolinite) can interact significantly with water. Thus, clay minerals and water can be treated as clay-water composites in the theoretical modeling of physical properties ( $\mathrm{Li}$ and Wong 2016). According to $\mathrm{Li}$ and Wong (2016), the volume fraction of clay-water composites, $f_{C W}$ in the soil can be derived as a function of clay fraction, $c_{f}$ and porosity, :

$$
f_{C W}=C_{f}(1-n)+n
$$

3

To visually characterize the structural state-changing behavior of soils using percolation theory, we randomly generate $a \mathrm{~L} \times \mathrm{L}(50 \times 50)$ lattice of points that are occupied with non-clay minerals and claywater composites with different volume fractions (Fig. 4). Two sites are treated as connected if they are the nearest neighbors (4 neighbors on square lattice), and a set of connected sites generate a cluster. A cluster that is spanning is called the spanning cluster, and the system is percolating if there is a spanning 
cluster in the system. As shown in Fig. 4, different pieces of clay clusters are represented by different colors. As we increase the volume fraction of clay-water composites, $f_{C w}$ the system tends to be percolated by clay-water composites.

The plot of the probability for there to be a connected path from one side to another, as a function of $f_{C W}$ for various system sizes $L$ is shown in Fig. 5 . The critical volume fraction of clay-water composites $f_{C W}$ for the percolation behavior is determined as 0.59 accordingly. Given Eq. (3), the critical clay fractions $C_{f}$ for soils can be derived at values of $0.32(=0.4)$ to $0.41(=0.3)$ depending on their porosities. Such critical clay fraction values are comparable with the structural state parameter A used in Eq. (1) for governing the transition point of the curve.

\subsection{Clay mineralogy}

Non-clay fractions of soils are mainly composed of quartz, and the friction property of non-clay fraction is slightly affected by some external factors such as the applied normal stress and the salinity of the pore fluid. However, the clay matrix can have a major variation of the clay minerals, and the external factors will exert a considerable impact on the friction properties. According to the measured residual friction angles of the clay matrix, $\phi_{r}{ }^{C}$ of a variety of soils with different clay mineralogy, the value of $\phi_{r}{ }^{C}$ for clay matrix significantly decreases with the increase of plasticity index (PI) (Fig. 6). It should be noted that we only use results of high clay fraction samples (with a clay fraction of more than 0.7 ) to illustrate the relation, which is to characterize the strength of the clay matrix. When $\mathrm{PI}$ is more than $50 \%$, there is little variation in $\phi_{r}{ }^{C}$ with the increase in PI. The modeled result and measured data give a good correlation between the plasticity index and residual frictional angle as shown in Fig. 6, which is consistent with the relationship illustrated by Voight (1973) and Tsiambaos (1991). The value of the plasticity index is an indicator of smectite minerals illustrated in Fig. 7, the clay matrix will have a PI value higher than $50 \%$ when the smectite fraction in clay $f_{S C}$ is more than 0.1 . Similar conclusions were made in the study of Tsiambaos (1991) based on the relations between residual strength and clay fraction or bentonite content of marls. The influence of the variation in clay mineral content on the residual strength was studied accordingly.

Taking water-saturated kaolinite and smectite minerals as an example, smectite particles will behave like the matrix filled in between kaolinite particles (Fig. 8). Even if at a small portion, those smectite particles still can prevent direct contact among kaolinite particles. Thus, the residual friction angle of clay matrix of different soils tends to have a constant value (5 degrees), because the smectite fraction in the clay of most landside soil is more than 0.1 . Thus, the relation between residual friction angle and clay fraction for general landslide soils can be approximated using a single relation shown in Fig. 3.

\subsection{Applied normal stress}

Experimental results by Eid et al. (2016) indicate that the residual friction angle of clay matrix decreases with the increase in the applied normal stress (Fig. 9). Such a decreasing trend is applicable for soils with different clay mineralogy. We use the PI value to represent the difference in clay mineralogy. It can be 
found that the normal effective stress has a major impact on the residual strength of the clay matrix when the stress is less than $200 \mathrm{kPa}$. The value of $\phi_{r}{ }^{C}$ tends to be constant when the applied normal stress is more than $200 \mathrm{kPa}$. It is because at lower stress level (i.e. $<200 \mathrm{kPa}$ ), clay particles have edge-toface type contact which plays a vital role during external loading. However, more face-to-face types of contact are generated at higher stress levels, which leads to a lower value of fraction angle. That is why we only include the results with large normal stress (more than $200 \mathrm{kPa}$ ) in Fig. 2c. It is to minimize the impact of the applied normal effective stress. From an engineering point of view, it is on the safe side to use the lower bound value of $\phi_{r}{ }^{C}$.

\subsection{Effect of pore fluid salinity}

According to Maio and Fenellif (1994), the residual strength of clays is affected by their mineral composition, and by the nature of their constituent pore fluid illustrated in Fig. 10, the residual strength of pure clay (clay matrix) mainly increases with an increase of the pore fluid salinity, which yields similar conclusions as compared to the findings in the study by Moore (1991). The shear strength of kaolin is not affected by the solutions used, whereas the residual strength of bentonite (rich in smectite) varies greatly because of the abundance of diffusion double layers. At a salinity of 6 moles, the water is fully saturated with sodium chloride solution. Except for pure bentonite, most of the clay matrices display a stable residual strength when the salinity is more than 1 mole.

We performed a statistical analysis on the pore fluid salinity of 39 soil samples from various depths of worldwide sites. Among them, 15 samples are from eastern Canada sensitive clay slopes (Locat and StGelais 2014), 9 samples are from Yama-ashi, Higashi-shiroishi and Ariake-kantaku in Japan (Egashira and Ohtsubo 1982), and 12 samples are from various locations of Norway (Rosenqvist 1953; Bjerrum 1954). As shown in Fig. 11, the pore fluid salinity displays a lognormal distribution. Most soils have a pore fluid salinity less than 0.1 mole, which indicates that the salinity is not a significant factor to be considered in analyzing the residual strength of soils.

\subsection{The inclusion of coarse-grained particles}

The proposed approach of estimating residual friction angle of land-sliding soils was only applied to soils not containing coarse-grained particles (e.g., gravel-sized particles and sand), and the recommended structural state parameters $A$ and $B$ values are suggested as 0.41 and 0.26 , respectively. However, some land-sliding zones also contain a substantial amount of coarse-grained particles (Wen et al. 2007). Based on the measured results from Wen et al. (2007), we use the proposed structural state approach to derive parameters $A$ and $B$ for soils containing coarse-grained particles (Fig. 12). In the experimental results by Wen et al. (2007), sandy soil samples, which are gravels free (i.e. gravel particle size larger than $2 \mathrm{~mm}$ removed) were used in reversal direct shear tests. Whereas in-situ direct shear tests were carried out on soils containing gravel size particles. Shown in Fig. 12, it is illustrated that the proposed structural state approach yields a good correlation between the modeled result and the experimental data of reversal direct shear tests, where gravel-free soils were used. It is also should be noted that the derived structural state parameters ( $A$ and $B$ ) are different from those from soils only containing fine-grained particles as 
displayed in Fig. 2. Thus, the inclusion of coarse-grained particles will significantly affect the values of structural state parameters, but the proposed approach is still effective if gravel-sized particles are not involved. For those in-situ direct tests result on soils containing gravel-sized particles, our modeled result does not match well with the measured data (Fig. 12). The variation in results of in-situ direct tests can be related to a large uncertainty in in-situ direct shear tests. More in-situ test data are needed for further investigation. Thereby, we do not suggest using the proposed structural state approach to estimate the residual strength of land-sliding soils with significant gravel-sized particles.

\section{Conclusions}

We propose a practical approach for estimating the residual friction angle of land-sliding soils. The approach considers the structural states quantitatively and applies the residual strengths of non-clay fraction and clay matrix as the major inputs. The percolation theory is used to physically explain the structural state transitional behavior in soils with different clay fractions. The effects of clay mineralogy, the applied normal stress, the salinity of the pore fluid, and the particle size of a nonclay fraction on the residual strengths of clay matrix are also analyzed. The results show that the approach can be used for predicting residual strengths of a wide range of soils that differ in geological origin. The proposed approach cannot completely replace the experimental measurement on the residual friction angles of soils in a studying area. Some of the key inputs in the model are dependent on the results of laboratory tests. However, the proposed approach can be applied efficiently to quantify the residual friction angles of soils with different clay fractions using the least number of experimental results.

\section{Declarations}

\section{Funding}

This work was supported by Natural Sciences and Engineering Research Council (NSERC) Discovery Grant Canada (NO. RGPIN-2017-05169).

\section{Conflicts of interest}

The authors have no conflicts of interest to declare. All co-authors have seen and agree with the contents of the manuscript. We certify that the submission is original work and is not under review at any other publication.

\section{Author Contributions}

Biao Li contributed to the study conception and design. Data collection and analysis were performed by Sohail Akhtar. The first draft of the manuscript was written by Biao Li and Sohail Akhtar. All authors read and approved the final manuscript.

\section{References}


1. Belokas G (2015) Correlating the residual strength to index properties. Geotechnical Engineering for Infrastructure and Development, Conference Proceedings: 3105-3110.

doi:10.1680/ecsmge.60678.vol6.484

2. Bishop AW (1971) Shear strength parameters for undisturbed and remolded soil specimens.

Proceedings of the Roscoe memorial symposium, Cambridge, Mass.: 3-58

3. Bjerrum L (1954) Geotechnical properties of Norwegian marine clays. Géotechnique 4 (2): 49-69. https://doi.org/10.1680/geot.1954.4.2.49

4. Cancelli A (1977) Residual shear strength and stability analysis of a landslide in fissured over consolidated clays. Bull. Int. Assoc. Eng. Geol 16: 193-197

5. Crawford BR, Faulkner DR, Rutter EH (2008) Strength, porosity, and permeability development during hydrostatic and shear loading of synthetic quartz-clay fault gouge. Journal of Geophysical Research: Solid Earth 113 (B3): B03207. doi: 10.1029/2006JB004634.

6. Chen XP, Liu D (2014) Residual strength of slip zone soils. Landslides 11 (2): 305-314. 10.1007/s10346-013-0451-z

7. Collotta T, Cantoni R, Pavesi U, Ruberl E, Moretti PC (1989) A correlation between residual friction angle, gradation and the index properties of cohesive soils. Géotechnique 39 (2): 343-346

8. Egashira K, Ohtsubo M (1982) Smectite in marine quick-clays of Japan. Clays and Clay Minerals, 30 (4): 275-280. https://doi.org/10.1346/CCMN.1982.0300404

9. Eid HT, Rabie KH, Wijewickreme D (2016) Drained residual shear strength at effective normal stresses relevant to soil slope stability analyses. Engineering Geology 204: 94-107. doi: https://doi.org/10.1016/j.enggeo.2016.02.003

10. Gibo S, Egashira K, Hayashi Y (1992) Measurement of residual strength of slip surface soil with a ring shear apparatus and its relation to physical and mineralogical properties of the soils. J. Japan Agricultural Engineering Society 159: 57-63

11. Horn HM, DeereDU (1962) Frictional characteristics of minerals. Geotechnique 12 (4): 319-335. https://doi.org/10.1680/geot.1962.12.4.319

12. Kalteziotis N (1993) The residual shear strength of some Hellenic clayey soils. Geotechnical and Geological Engineering 11 (2): 125-145. doi: 10.1007/bf00423339

13. Kanji MA (1974) The relationship between drained friction angles and Atterberg limits of natural soils. Géotechnique 24 (4): 671-674. doi: 10.1680/geot.1974.24.4.671

14. Li B, Wong RCK (2016) Quantifying structural states of soft mudrocks. Journal of Geophysical Research: Solid Earth 121 (5): 3324-3347. doi: 10.1002/2015JB012454

15. Li B, Wong RCK (2017a) Modeling anisotropic static elastic properties of soft mudrocks with different clay fractions. Geophysics 82 (1): MR27-MR37. doi:10.1190/geo2015-0575.1

16. Li B, Wong RCK (2017b) A mechanistic model for anisotropic thermal strain behavior of soft mudrocks. Engineering Geology, 228: 146-157. doi:http://dx.doi.org/10.1016/j.enggeo.2017.08.008 
17. Locat J, St-Gelais D (2014) Nature of sensitive clays from Quebec. In sensitive clays: From geoscience to risk management, L'Heureux JS, Locat A., Leroueil S., Demers D. and Locat J. edition, Springer, Dordrecht, Netherlands : 25-37

18. Lupini JF, Skinner AE, Vaughan PR (1981) The drained residual strength of cohesive soils. Geotechnique 31 (2): 181-213

19. Maio CD, Fenellif GB (1994) Residual strength of kaolin and bentonite: the influence of their constituent pore fluid. Géotechnique 44 (2): 217-226. doi: 10.1680/geot.1994.44.2.217.

20. Malthe-Sorenssen A (2015) Percolation and disordered systems - A numerical approach. Springer, Norway: pp. 4-10

21. Mesri G, Cepeda-Diaz AF (1986) Residual shear strength of clays and shales. Geotechnique 36 (2): 269-274

22. Moore R (1991) The chemical and mineralogical controls upon the residual strength of pure and natural clays. Geotechnique 41 (1): 35-47

23. Nakamura S, Gibo S, Egashira K, Kimura S (2010) Platy layer silicate minerals for controlling residual strength in landslide soils of different origins and geology. Geology 38 (8): 743-746. doi: 10.1130/G30908.1

24. Ren S, Zhang Y, Xu N, Wu R, Liu X, Du G (2021) Mobilized strength of gravelly sliding zone soil in reactivated landslide: a case study of a giant landslide in the north-eastern margin of Tibet Plateau. Environ. Earth Sci. 80, 1-15. https://doi.org/10.1007/s12665-021-09638-y

25. Rosenqvist ITH (1953) Considerations on the sensitivity of Norwegian quick-clays. Géotechnique 3 (5), 195-200. https://doi.org/10.1680/geot.1953.3.5.195

26. Salimi SN, Yazdanjou V, Hamidi A (2008) Shape and size effects of gravel grains on the shear behavior of sandy soils. Landslides and Engineered Slopes. From the Past to the Future, pp. 469-474

27. Skempton AW (1985) Residual strength of clays in s, folded strata and the laboratory. Géotechnique 35 (1): 3-18

28. Stark TD, Eid HT (1994) Drained residual strength of cohesive soils. Journal of Geotechnical Engineering 120 (5): 856-871. https://doi.org/10.1680/geot.2001.51.3.197

29. Stark TD, Hussain M (2010) Shear strength in preexisting landslides. Journal of Geotechnical and Geoenvironmental Engineering 136 (7): 957-962. doi:10.1061/(ASCE)GT.1943-5606.0000308

30. Stark TD, Hussain M (2013) Empirical correlations: drained shear strength for slope stability analyses. Journal of Geotechnical and Geoenvironmental Engineering 139 (6): 853-862. doi:10.1061/(ASCE)GT.1943-5606.0000824

31. Suzuki M, Tsuzuki S, Yamamoto T (2007) Residual strength characteristics of naturally and artificially cemented clays in reversal direct box shear test. Soils and Foundations. 47 (6):1029-44

32. Tembe S, Lockner DA, Wong TF (2010) Effect of clay content and mineralogy on frictional sliding behavior of simulated gouges: Binary and ternary mixtures of quartz, illite, and montmorillonite. Journal of Geophysical Research: Solid Earth 115 (B3): B03416. doi: 10.1029/2009jb006383 
33. Tiwari B, Marui H (2003) Estimation of residual shear strength for bentonite-kaolin-Toyoura sand mixture. Journal of the Japan Landslide Society 40 (2):124-133

34. Tiwari B, Marui H (2001) Shearing behaviour of landslide sliding surface and main scarp soil during drained ring shear test. Proc., 15th International Conference on Soil Mechanics and Geotechnical Engineering, Istanbul, Turkey 1: 295-298

35. Tiwari $\mathrm{B}$, Marui $\mathrm{H}$ (2004) Objective oriented multi-stage ring shear test for the shear strength of landslide soil. J. Geotech. Geoenviron. Eng 1302: 217-222

36. Tiwari B, Marui H (2005) A new method for the correlation of residual shear strength of the soil with mineralogical composition. J. Geotech. Geoenviron. Eng 131 (9): 1139-1150. doi:

10.1061/(ASCE)1090-0241(2005)131:9(1139)

37. Townsend BF, Gilbert PA (1973) Tests to measure residual strengths of some clay shales. Géotechnique 23 (2): 267-271

38. Tsiambaos G (1991) Correlation of mineralogy and index properties with residual strength of Iraklion marls. Engineering Geology 30: 357-369

39. Tsifoutidis G (1993) Intrinsic properties of Hellenic Marls. PhD Thesis, Durham University.

40. Voight B (1973) Correlation between Atterberg plasticity limits and residual shear strength of natural soils. Géotechnique 23 (2): 265-267

41. Wen BP, Aydin A, Duzgoren-Aydin NS, Li YR, Chen HY, Xiao SD (2007) Residual strength of slip zones of large land slides in the Three Gorges area, China. Engineering Geology 93 (3): 82-98. doi: https://doi.org/10.1016/j.enggeo.2007.05.006

42. Wesley LD (2003) Residual strength of clays and correlations using Atterberg limits. Géotechnique 53 (7): 669-672. doi: 10.1680/geot.2003.53.7.669

43. Yin H (1992) Acoustic velocity and attenuation of rocks: isotropy, intrinsic anisotropy, and stress induced anisotropy. PhD thesis, Department of Geophysics, Stanford University, Stanford, CA

44. Zhang Y, Guo C, Lan H, Zhou N, Yao X (2015) Reactivation mechanism of ancient giant landslides in the tectonically active zone: a case study in Southwest China. Environ. Earth Sci. 74, 1719-1729. https://doi.org/10.1007/s12665-015-4180-6

\section{Figures}




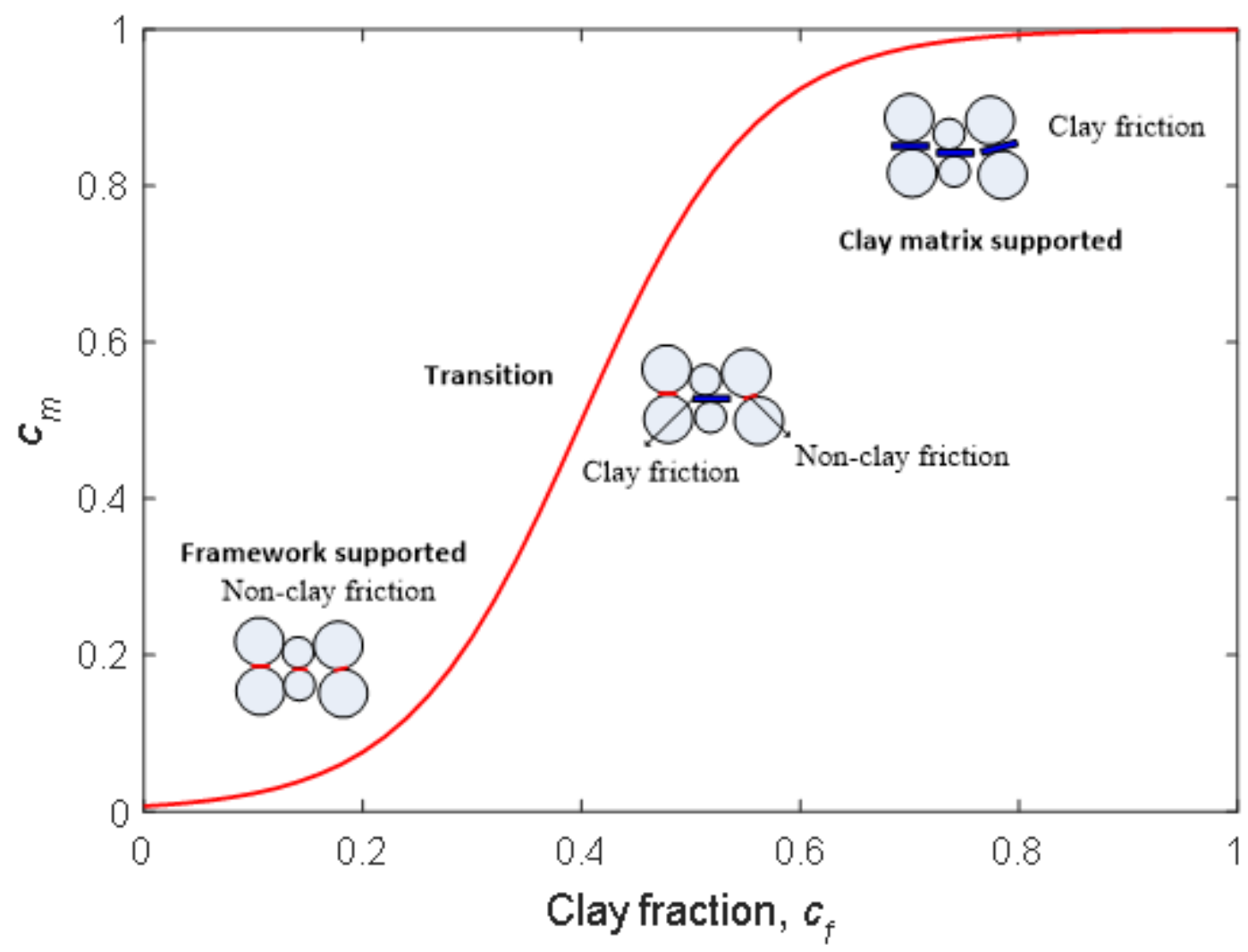

Figure 1

Sketch showing the structural state coefficient as a function of clay fraction. 

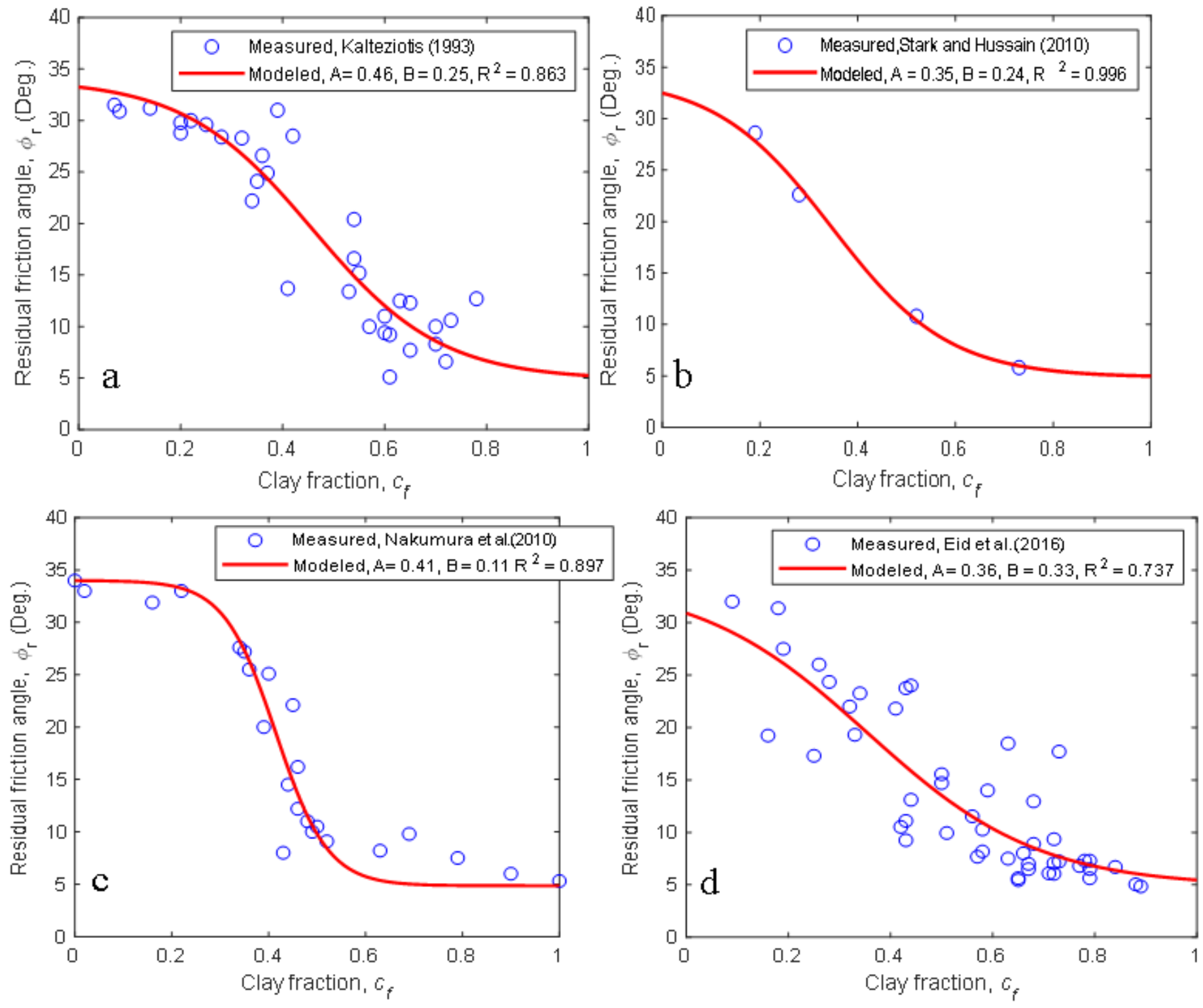

Figure 2

Measured and modeled relations between residual friction angle and clay fraction for land-sliding soils from different sites (in c, some nonclay platy layer silicate minerals are also treated as parts of the clay group). 


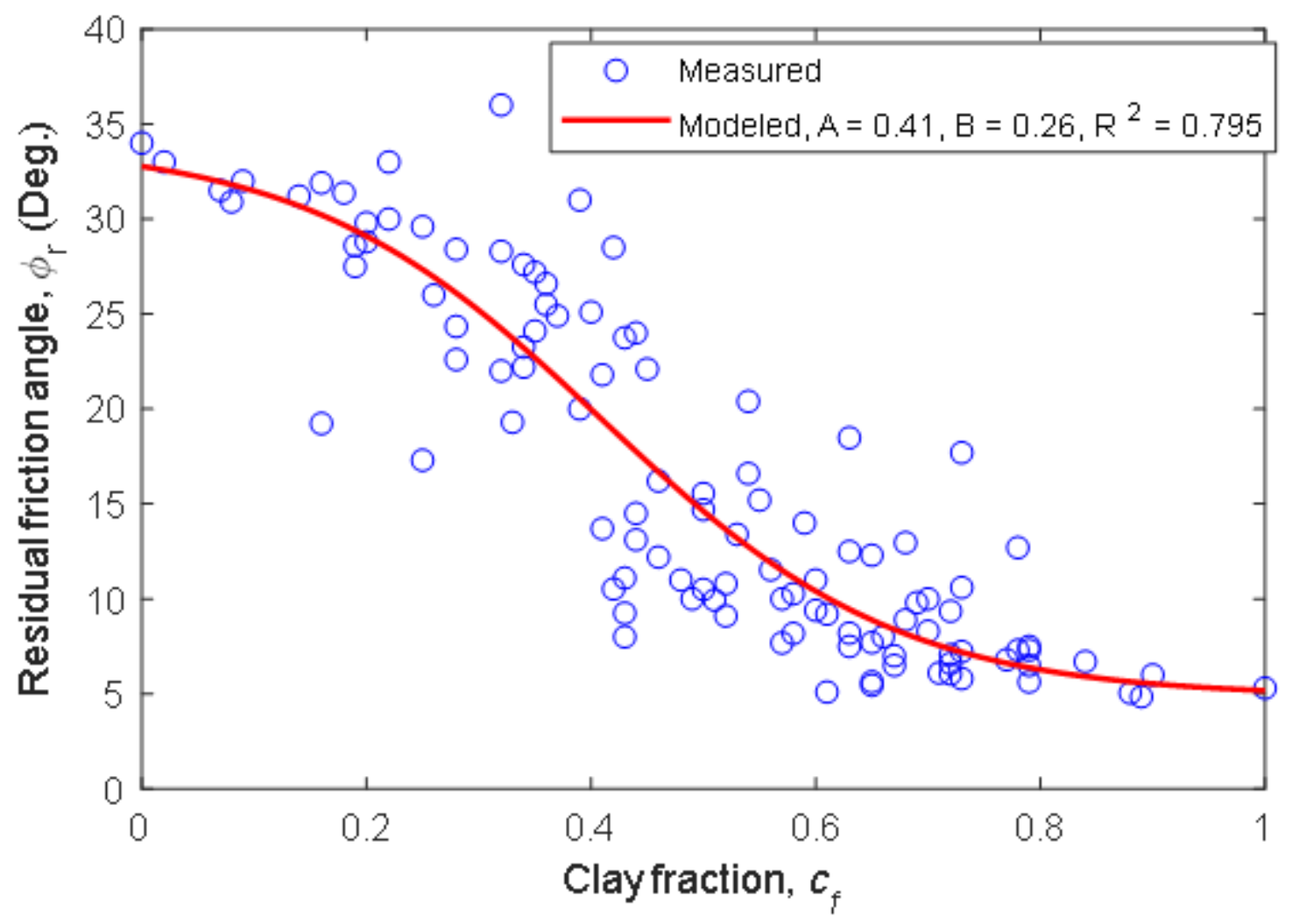

Figure 3

Measured and modeled the relation between residual friction angle and clay fraction for general soils.
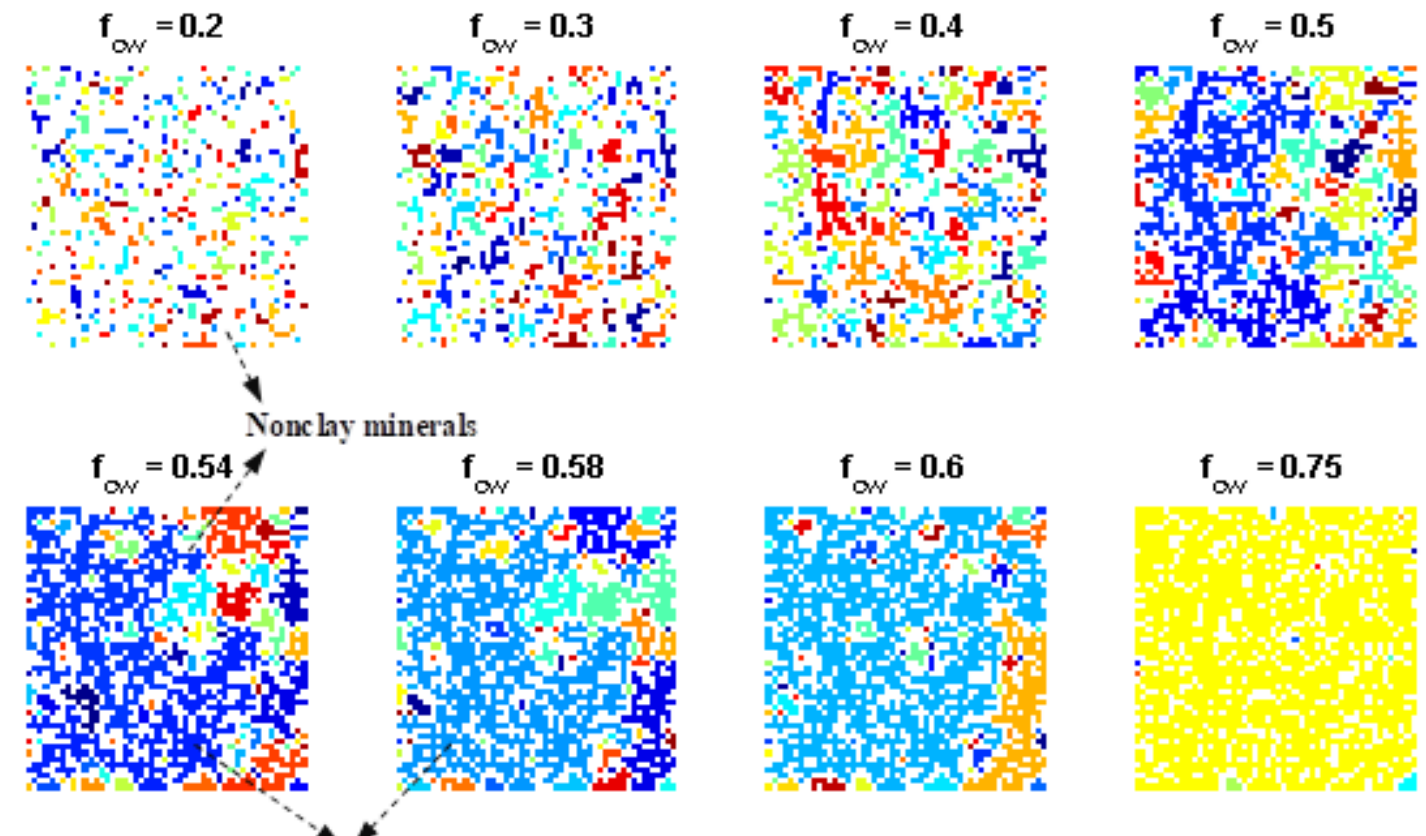

Spanning clay cluster

Figure 4 
Plot of the clay clusters in a $50 \times 50$ lattice system for various values of volume fraction of clay-water composites $\mathrm{f}_{\mathrm{cW}}$ (different pieces of clay clusters are represented by different colors).

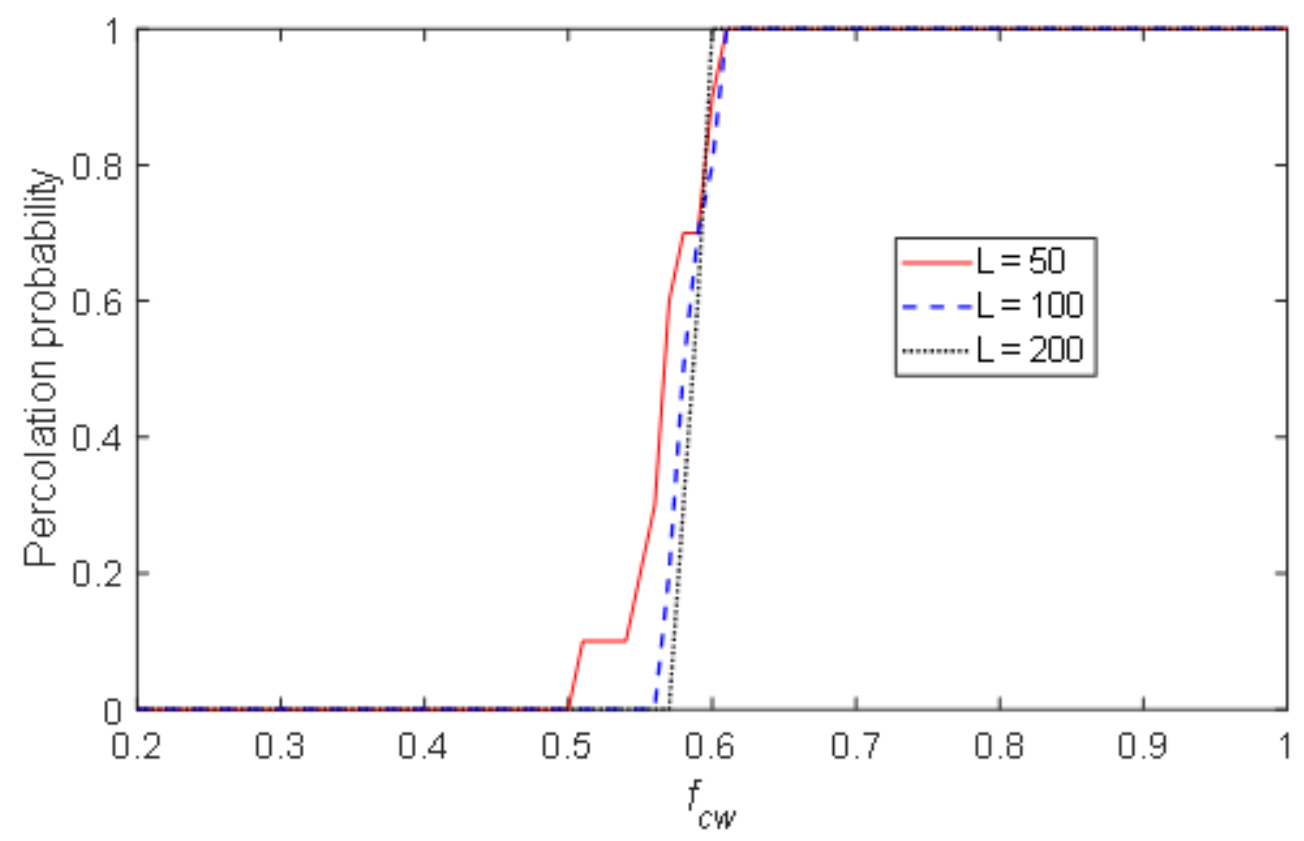

\section{Figure 5}

Plot of percolation probability as a function of $f_{c w}$ for various system sizes $L$.

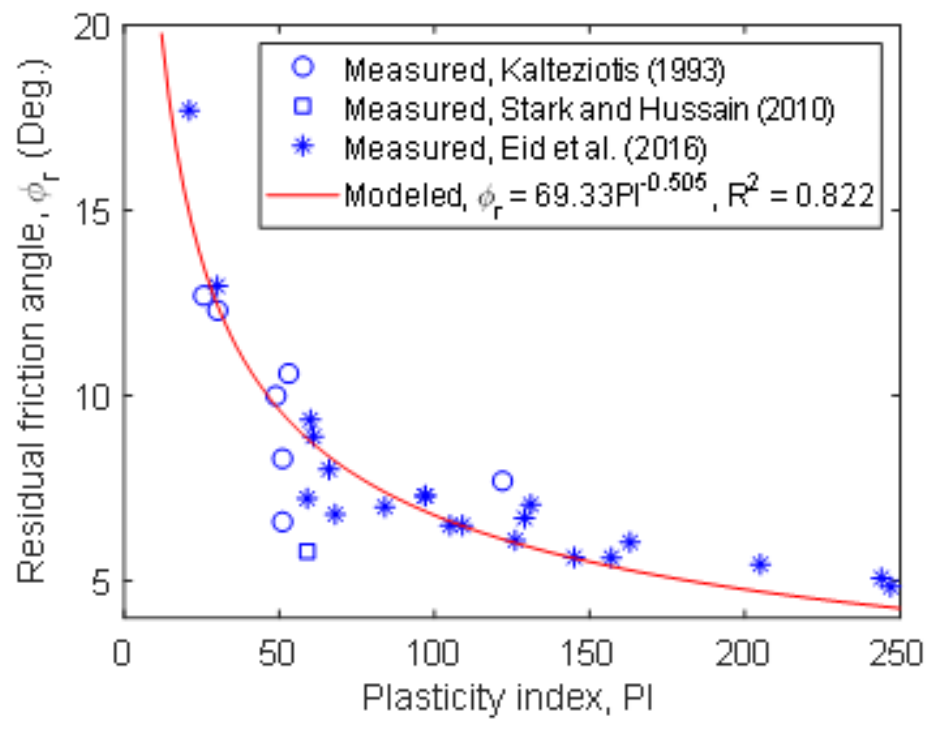

\section{Figure 6}

Measured and modeled the relation between residual friction angle and plasticity index of clay matrix. 


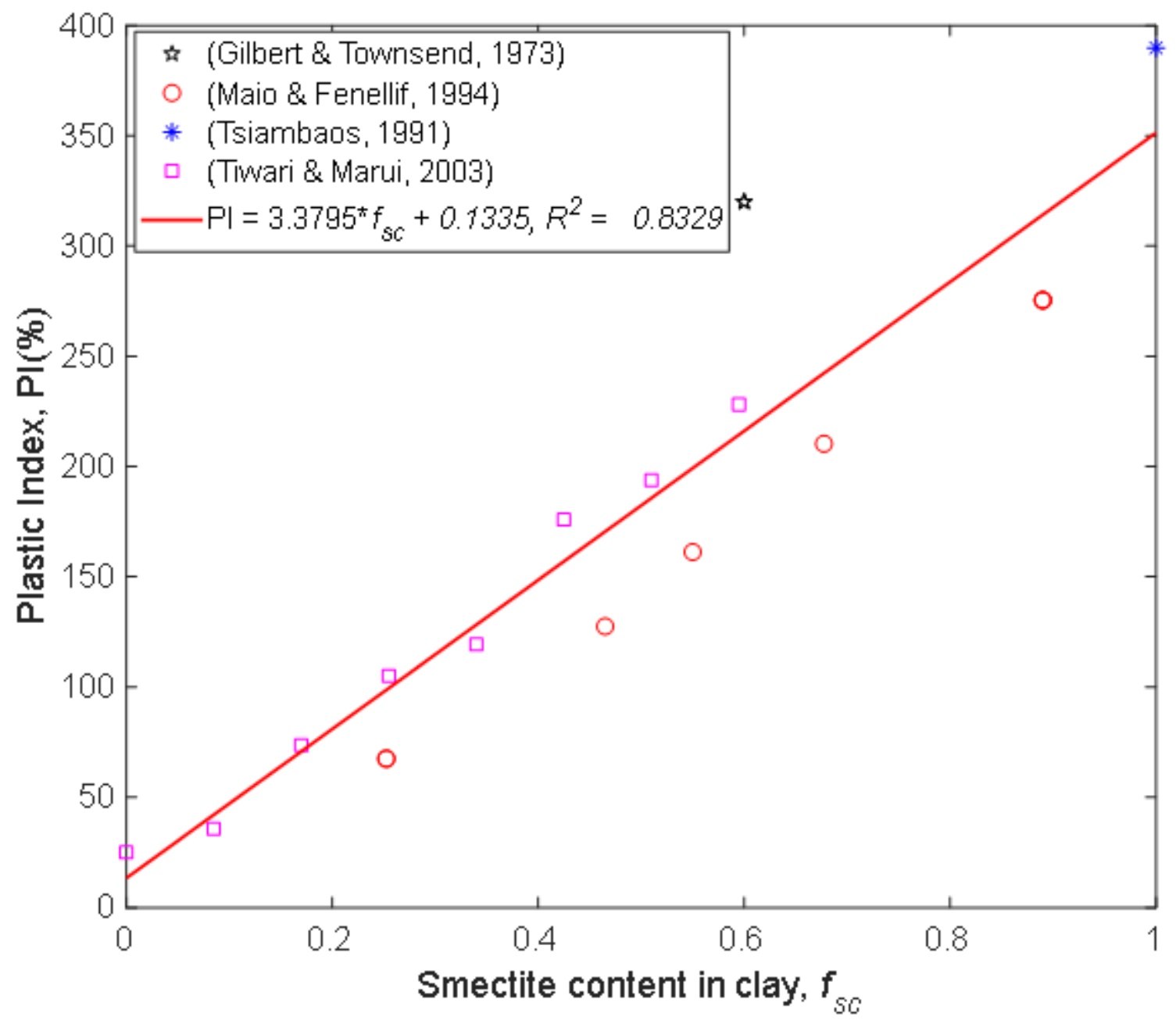

Figure 7

Measured and modeled relation between the plasticity index of clay matrix and the smectite fraction in clay minerals.

Kaolinite

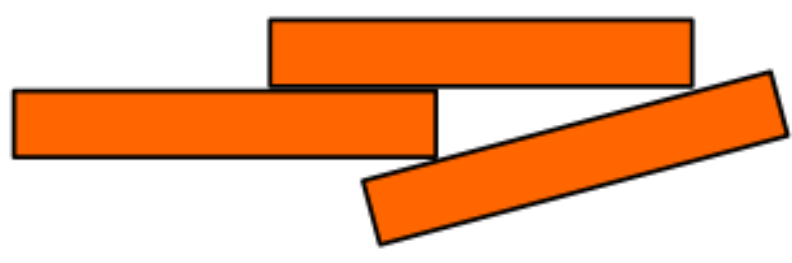

Kaolinitemixed with smectie

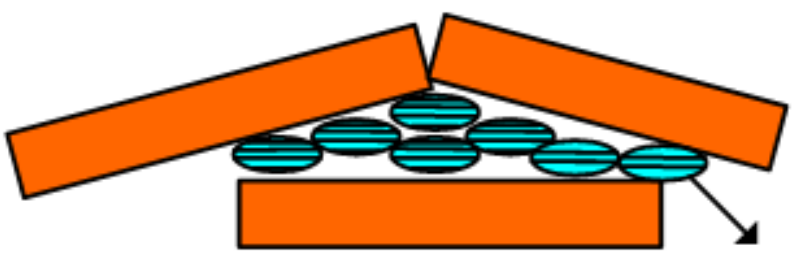

Smectite

Figure 8

Sketch showing the structure of pure kaolinite and kaolinite-smectite mixture. 


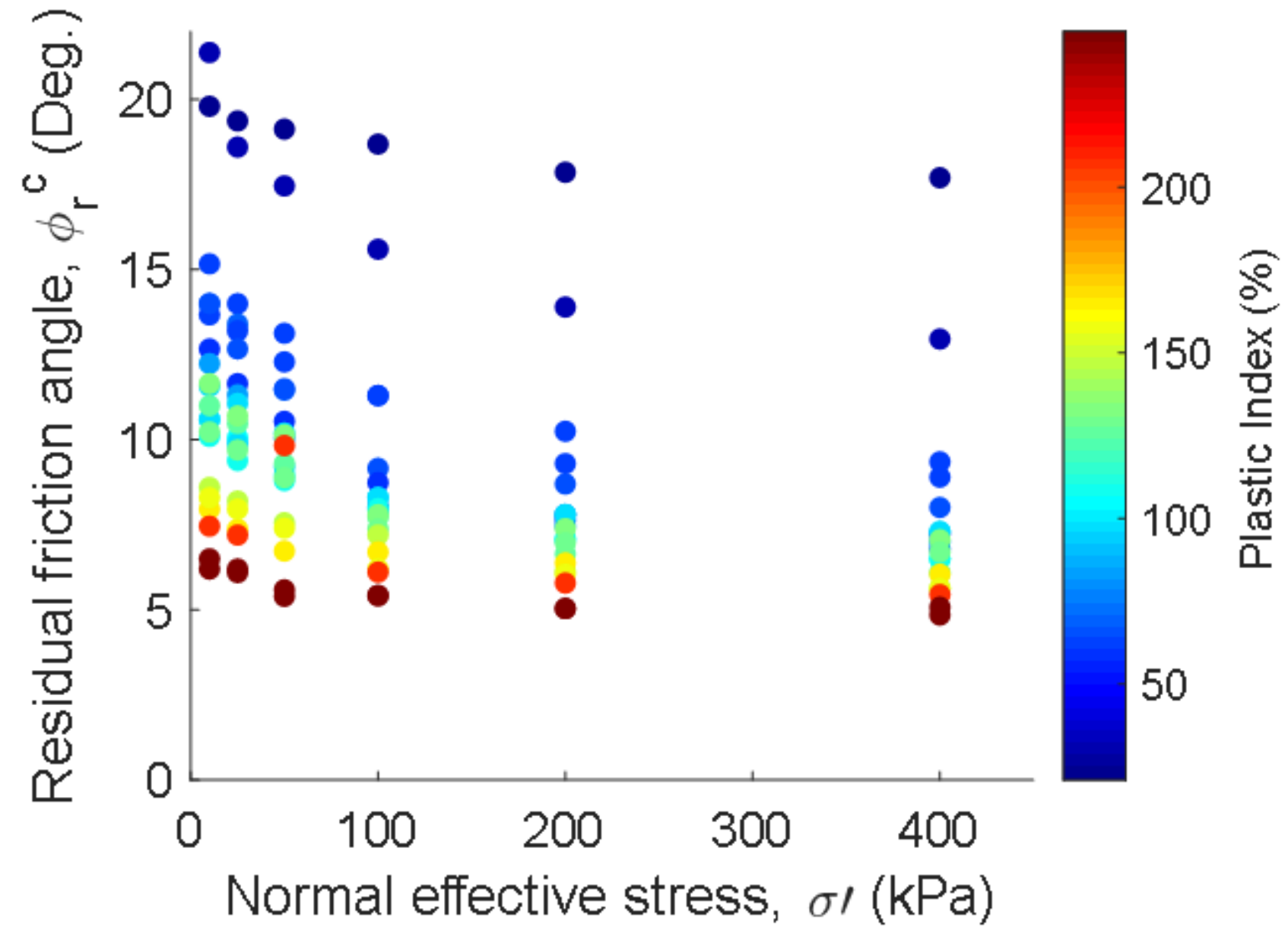

Figure 9

Measured residual strengths of clay matrix at different normal effective stresses, measured data are from Eid et al. (2016). 


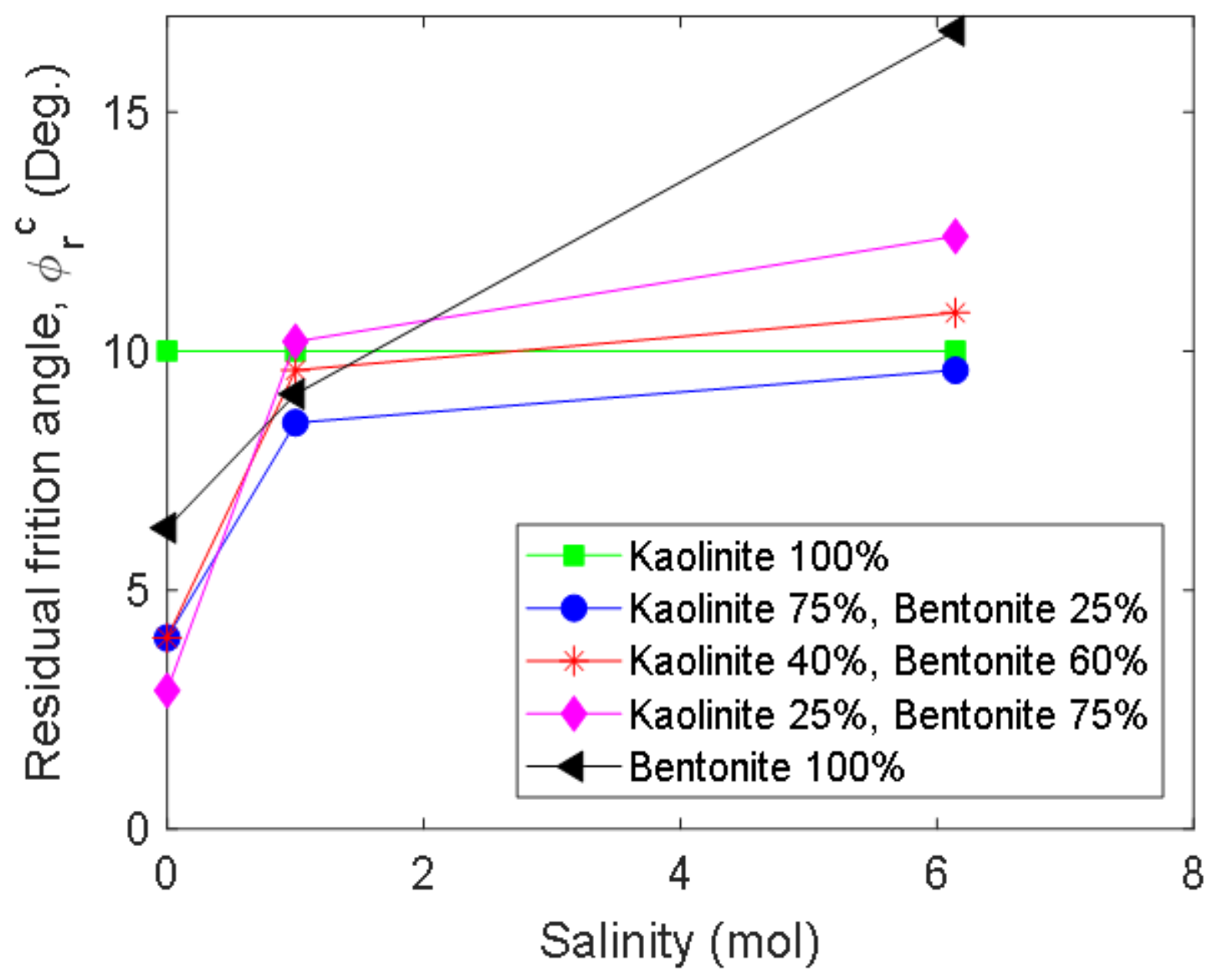

Figure 10

Measured residual strengths of synthetic clay soils at different salinities, measured data are from Maio and Fenellif (1994). 


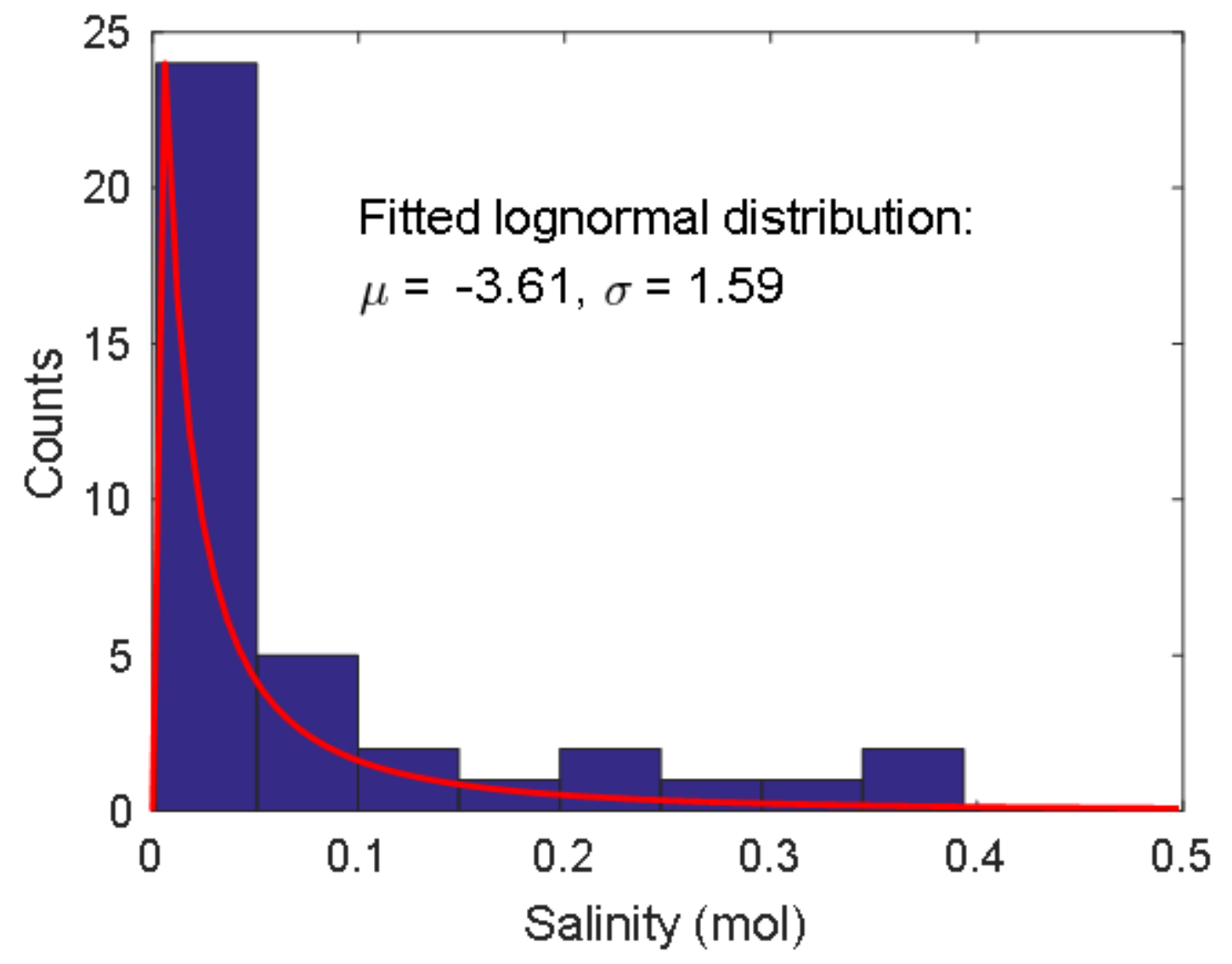

Figure 11

Pore fluid salinity of soils from sites with different geological origins. 


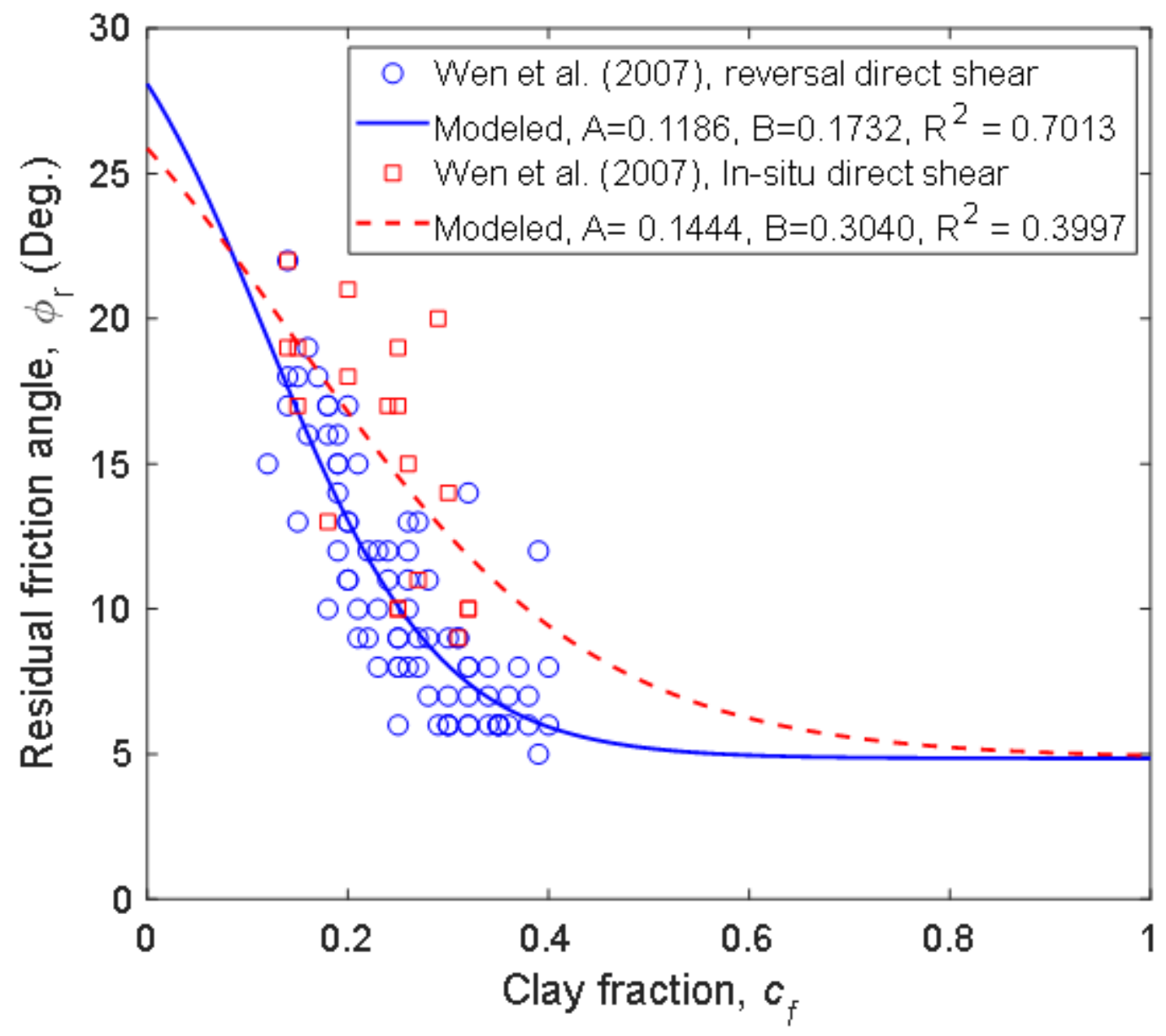

Figure 12

Measured and modeled relation between residual friction angle and soil containing coarse-grained particles (i.e. gravel, sand) for landslide soils. 